\title{
Factors Related to Perceived Life Satisfaction Among the Elderly in South Korea
}

\author{
Minsoo Jung ${ }^{1}$, Carles Muntaner ${ }^{2}$, Mankyu Choi ${ }^{3}$ \\ ${ }^{1}$ Department of Health Policy and Management, School of Public Health, Seoul National University; ${ }^{2}$ Center for Addictions and Mental \\ Health, University of Toronto; ${ }^{3}$ Department of Healthcare Management, College of Health Science, Korea University
}

\begin{abstract}
Objectives: This study attempted to explore the aging phenomena that now characterize much of Korean society, and assessed issues associated with the life satisfaction experienced during the process of aging.

Methods: By employing the National Survey on the State of Life and the Desire for Welfare of the Elderly, 2004 in South Korea this study attempted to identify the factors that determine subjective life satisfaction among the elderly. The data utilized herein consisted of 3278 elderly people aged 65 years or older, from 9308 households.

Results: The results of analysis from the final model after the introduction of 19 variables in 8 factors showed statistically similar explanatory power in men (adj. $\left.R^{2}=0.320\right)$ and in women (adj. $\left.R^{2}=0.346\right)$. We found that economic condition was the most influential factor in both men $(B=0.278)$ and women $(B=0.336)$ except perceived health condition variables. The second most influential variable in life satisfaction was health checkups in men $(B=0.128)$ and degree of nutritional diet in women $(B=0.145)$. Those who had experience with chronic diseases also reported significantly lower perceived life satisfaction and this was particularly true of women.

Conclusions: The aging society requires an understanding of the lives of elderly individuals. This study explored factors associated with life satisfaction in old age by using a life satisfaction model. The success of an aging society begins with an accurate understanding of the elderly, and thus political attention will need to be focused on this matter.
\end{abstract}

Key words: Aged, Life satisfaction, Social support, Chronic disease, Socioeconomic position, South Korea J Prev Med Public Health 2010;43(4):292-300

\section{INTRODUCTION}

Aging has been generally conceptualized as merely a numerical matter of advanced age, and studies in this field have been based on numerical age rather than individuals' own subjective perceptions of age. However, this approach is fairly limited, insomuch as each individual may have a different physical health age and a different perception of the age at which he or she should be considered elderly. Moreover, elderly individuals tend to be more sensitive to their life satisfaction and health conditions, depending on their socioeconomic situations, as they tend to have relatively limited work performance [1-4].

These days, however, new variables have been suggested which are associated specifically with the elderly population, including the experience of diseases, age-identity, and social participation [5]. Although these factors do not in and of themselves produce health results, they do tend to improve mental satisfaction and physical health, as the result of their catalytic and indirect effects [6-10]. According to the results of a previous study, the higher is an individual's capability to engage in daily living activities, the higher will be the self-respect of the individual, and the higher the individual's self-respect is, the better the individual's subjective health condition will be [10]. Also, the number of chronic diseases in the elderly individual is a critical indicator of the objective health condition; this number increases with decreasing social support, and the number decreases when the individual receives more social support [11-13].

Meanwhile, it is also crucial to assess the factors that affect the age at which elderly individuals begin to identify themselves as elderly. Usually, these factors involve a combination of physical aging and social factors, such as retirement [1]. However, individuals entering the aging stage are deluged with new images of the so-called 'young elderly'--a notion involving light eating, regular exercise, balanced nutritional intake, and continuous social activity. Although these positive selfimages clearly exert some influence on the elderly population, there is a problem in that studies of elderly issues tend to make rather hasty generalizations about the process of aging as experienced by elderly individuals. Different individuals have different 
educational experiences during adolescence, and also differ in terms of ages of maturity, economic situation, health behavior, and family structures. The elderly stage of life is the time during which these factors have more pronounced effects on life. The impacts of these factors tend to be even greater when the elderly individual is no longer married, and is living as a single person [1,3].

In Korea, new critical views have begun to emerge, focusing largely on social definitions of images of the elderly, as well as the reproduction of specific issues [14]. It has been asserted by many that we should reject the process of "otherization" into certain images, which estranges elderly individuals from the middle-aged, and rather should attempt to understand them as they are, via this politico-economic approach. For example, when we identify the elderly as a burden in terms of social welfare expenditure, generational conflicts will continue to affect an aging society. Studies into life satisfaction in elderly individuals are clearly meaningful in this regard. Generally the elderly experience changed social and economical circumstances after retirement, and this causes a change in their feelings regarding degrees of happiness; this varies with level of social activity, the presence of chronic disease, activities of daily living (ADL), and age-identity. If we review the manner in which these subjective indices are associated with life satisfaction in the elderly, we can understand in a more meaningful way what old age really is.

The life satisfaction model can be used as a meaningful indicator, which reflects the individual's subjective health condition and is highly consistent with social reality [15]. Health behavior and general health level are both known to function as catalysts in this process. However, the perception of life satisfaction also differs among different age groups, genders, and family structures. First, each age group plays a different role, as has been shown in studies of ageism. Second, men and women experience different social lives and undergo different cognitive processes. Third, from the standpoint of family structure, which is emphasized heavily in East Asia, the parent-children relationship is pivotal to life satisfaction in cases in which the parents are living with and supported by their children. The purpose of this study is to analyze the factors constructing life satisfaction in the elderly population and explore its implications on public health to contribute in developing social policies for the Korean ageing society.

\section{METHODS}

\section{Data}

This study is premised on the cross-sectional data collected in the "National Survey on the State of Life and the Desire for Welfare of the Elderly, 2004" [16]. This survey is the only national statistical study of seniors in Korea conducted under the auspices of the Ministry of Health and Welfare, and is performed every 4 years. A study sample consisting of 3278 / 3482 elderly people (1255 men and 2023 women) of age 65 or older was prepared from individual questionnaires, which were sent to 9308 households in 180 locations throughout the country (completion rate: $89.9 \%$ ). The sample was taken from the Population and Housing Census, and the sample data were divided into six different areas according to housing characteristics (family housing, apartments) and administrative districts (large cities, middle and small cities, rural districts) via a proportional stratified sampling technique. The weighted sample total method was employed to correct the number of the seniors, reflecting the non-visit household rate and incompletion survey rate by each enumerated district.

The questions on the questionnaire addressed the family structure and the type of household, income and vocation, dependency status, and the health and social activities of the elderly respondent. In this study, combined data on individual elderly persons and households were utilized in our analyses.

\section{Measurements}

The response variables included life satisfaction, which is representative of the individual's subjective sense of happiness, and this was measured on a 5-point Likert scale [16-18]. The questions administered were similar to the general life satisfaction questions asked in the Korean version of the World Health Organization's Quality of Life (WHOQoL) survey; the results were verified in terms of their consistency and reliability [19, 20].

Explanatory variables are principally predicated on the model of the level of health and social support originally devised by Choe et al. [2]. For the purposes of this study, this model was further itemized into demographic factors (age, marital status), socioeconomic factors (educational level, employment status, economic situation), family factors (type of household, existence or 


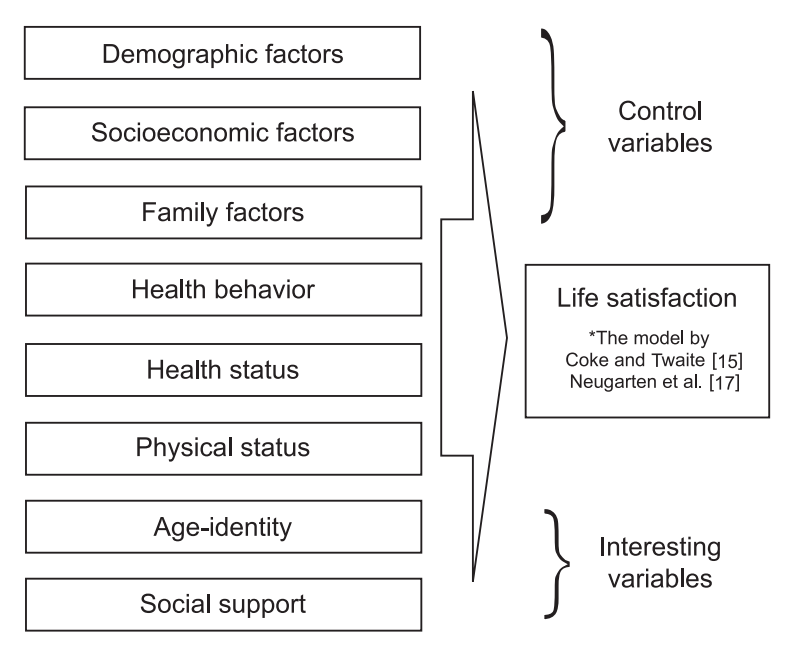

Figure 1. Framework of this study.

* 'Physical status: (the activities of daily living and cognitive function)' used the provided configuration variable by research data. However, 'social support' was made by using M2 item of the data, five variables which are used for this is generally in common use as variable to measure the social participation (the old man's religion, culture, sports, social, and whether participation of political groups).

not of persons requiring care), health behavior (smoking, drinking, exercise), health status (degree of nutritional diet, reception or not of health checkup, health condition compared with the same age group), physical status (number of chronic diseases, capability of activities of daily living, cognitive function), age-identity (perception on the age of the elderly), and social support (frequency of contact with children, performance or not of social activities)(Figure 1). The binomial variables were as follows: marital status (reference group: not a couple), employment status (reference group: none), experience of a fall (reference group: none), health checkup (reference group: no), existence or not of persons requiring care (reference group: none), and performance or not of social activities (reference group: none). Additionally, educational level, economic situation, effort to maintain a nutritional diet, and health condition as compared with the same age group and the number of social contacts measured on a 5-point Likert scale; smoking, drinking, and performance of exercise or lack thereof were measured on a 3-point scale.

The 'Survey on the Elderly' included questions regarding the $\mathrm{ADL}$, and required responses consisting of one of 3 answers (independent, partially dependent, dependent) for 12 factors (clothing on/off, face washing, tooth brushing, bathing, eating, changing posture, sitting up, changing seat, exiting the room, using a toilet, bowel

Table 1. Means and standard deviations (SD) of continuous variables used

\begin{tabular}{|c|c|c|c|}
\hline Characteristics & $\mathrm{n}$ & Mean & $\mathrm{SD}$ \\
\hline Age $(y)$ & 3278 & 74.3 & 6.4 \\
\hline Age of matrimonial end & 1450 & 54.5 & 14.7 \\
\hline Duration lived without a spouse & 1450 & 22.1 & 15.2 \\
\hline Number of living sons & 3278 & 2.3 & 1.9 \\
\hline Number of living daughters & 3278 & 2.3 & 2.0 \\
\hline Number of total living children & 3136 & 4.0 & 1.7 \\
\hline Number of co-resident sons & 3278 & 0.3 & 0.5 \\
\hline Number of co-resident daughters & 3278 & 0.1 & 0.3 \\
\hline Number of co-resident unmarried children & 3278 & 0.2 & 0.4 \\
\hline Number of co-resident married children living together & 3278 & 0.3 & 0.5 \\
\hline Number of sons who do not live together & 3278 & 1.9 & 1.3 \\
\hline Number of daughters who do not live together & 3278 & 1.9 & 1.4 \\
\hline Number of unmarried children who do not live together & 3278 & 0.2 & 0.5 \\
\hline Number of married children who do not live together & 3278 & 3.6 & 1.8 \\
\hline Total number of sons & 3278 & 2.2 & 1.3 \\
\hline Total number of daughters & 3278 & 2.0 & 1.4 \\
\hline Total number of unmarried children & 3278 & 0.4 & 0.7 \\
\hline Total number of married children & 3278 & 3.8 & 1.8 \\
\hline Frequency of contact with children* & 3278 & 0.5 & 20.3 \\
\hline Frequency of other contacts with children* & 3278 & 2.0 & 20.6 \\
\hline Average monthly allowance (unit: \$10) & 3025 & 13.3 & 18.6 \\
\hline Average monthly income (unit: \$10) & 3018 & 48.6 & 67.4 \\
\hline Subjective level of health condition compared with the same age group ${ }^{+}$ & 3029 & 1.9 & 1.2 \\
\hline Number of chronic diseases & 3278 & 3.2 & 2.4 \\
\hline Degree of burdensome of medical expenses on chronic diseases ${ }^{\dagger}$ & 2042 & 2.2 & 1.2 \\
\hline 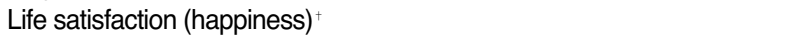 & 3011 & 2.2 & 1.0 \\
\hline Weight (kg) & 3047 & 56.7 & 10.4 \\
\hline Height (cm) & 3177 & 155.6 & 9.7 \\
\hline
\end{tabular}

* 9-point Likert scale (8: meet almost everyday, 0 : never),${ }^{+} 5$-point Likert scale (5: very satisfied, 1 : very dissatisfied)

+ 5-point Likert scale (5: very burdensome, 1: rarely burdensome). 
movement control, urination control). In this study, we have divided the total points for each question by the number of questions and again by the highest points among the answers, then multiplied the result by 100 (Cronbach's $\alpha=0.966$ ). Cognitive function (CF) was also introduced from the 'Survey on the Elderly' of 2004, in which 9 questions were administered regarding the existence of memory and $\mathrm{CF}$, all of which required yes/no responses. Total points were also adjusted to 100 centered $(\alpha=0.865)$.

\section{Data Analysis}

Analysis was conducted as follows: First, the characteristics of the sample of elderly individuals were assessed for each variable using descriptive statistics, and the conditions of elderly individuals with chronic diseases were also reviewed. Second, hierarchical multiple regression analysis was conducted by gender. This method is appropriate for this study, in that the effects and coefficient values of each factor on life satisfaction and the amount of change (increase/ decrease) in the $\mathrm{R}^{2}$ value are provided in comparable forms. 8 factors were introduced in order, taking into consideration the chronological order of their effects on life satisfaction and their theoretically established importance.

\section{RESULTS}

\section{General Characteristics of Study Subjects}

The characteristics identified in the sample group were as follows (Table 1): The average age was 74.2, and their matrimony had generally ended when the individual was approximately 54 years of age. $1450(44.2 \%)$ of the single subjects had lived without a spouse for approximately 22 years (average). The average number of living children was 3.9, and the number of co-resident children was 0.3 ; these were usually male children. The average number of children not living with the subject was 1.9. The frequency of contact with the children was one per 6 months on average, and the frequency of meeting was less than once per year. Many of the study subjects did not report having contact with their children. The average monthly income of the subjects was approximately 480 thousand won, and each elderly individual had an average of 3.2 chronic diseases. Subjective life satisfaction was measured at an average of 2.2 on the Likert scale.
Table 2. Health and living conditions of the elderly

\begin{tabular}{|c|c|c|}
\hline Characteristics & $\begin{array}{c}\text { Fre- } \\
\text { quency }\end{array}$ & $\%$ \\
\hline \multicolumn{3}{|l|}{ Education level } \\
\hline Illiteracy & 629 & 19.2 \\
\hline No education but knows how to read & 684 & 20.9 \\
\hline Elementary school & 1145 & 35.0 \\
\hline Middle school & 314 & 9.6 \\
\hline Over high school & 503 & 15.4 \\
\hline \multicolumn{3}{|l|}{ Do you have children/grandchildren who are alive? } \\
\hline No & 124 & 3.8 \\
\hline Yes & 3151 & 96.1 \\
\hline \multicolumn{3}{|l|}{ Do you have siblings who are alive? } \\
\hline No & 743 & 22.7 \\
\hline Yes & 2534 & 77.3 \\
\hline \multicolumn{3}{|l|}{ What is your current type of household? } \\
\hline Living with your married child & 892 & 27.2 \\
\hline Living alone although you have married children & 2266 & 69.1 \\
\hline No married children & 115 & 3.5 \\
\hline \multicolumn{3}{|l|}{ Do you have an occupation? } \\
\hline No & 2335 & 71.2 \\
\hline Yes & 943 & 28.8 \\
\hline \multicolumn{3}{|l|}{ Do you smoke? } \\
\hline Never & 1953 & 59.6 \\
\hline Quitted & 750 & 22.9 \\
\hline Currently smoking & 575 & 17.5 \\
\hline \multicolumn{3}{|l|}{ Do you drink? } \\
\hline Never & 1601 & 48.9 \\
\hline Quitted & 587 & 17.9 \\
\hline Currently drinking & 1089 & 33.2 \\
\hline \multicolumn{3}{|l|}{ Do you exercise? } \\
\hline Never & 2063 & 62.9 \\
\hline Occasionally & 315 & 9.6 \\
\hline Regularly & 900 & 27.5 \\
\hline \multicolumn{3}{|l|}{ Have you had a health checkup? } \\
\hline \multicolumn{3}{|l|}{ No } \\
\hline Yes & 1651 & 50.4 \\
\hline \multirow{2}{*}{\multicolumn{3}{|c|}{$\begin{array}{l}\text { Are you currently suffering from at least one chronic } \\
\text { disease? } \\
\text { No }\end{array}$}} \\
\hline & & \\
\hline Yes & 2988 & 91.2 \\
\hline
\end{tabular}

Next, the frequencies and percentages of a variety of factors were evaluated (Table 2). $35 \%$ of the subjects had an educational level of "elementary school graduate" and $39.3 \%$ reported no education. $22.7 \%$ had no living siblings, and $69.1 \%$ had married children who were not co-resident. $28.8 \%$ were employed, $17.5 \%$ were smokers, and $27.5 \%$ engaged in regular exercise.

Finally, the type and status of chronic diseases were investigated for 2988 subjects (91.2\%), all of whom had experienced at least one chronic disease (Table 3 ). The chronic diseases suffered by the elderly were, in order of frequency: arthritis (42.7\%), hypertension (40.1\%), backache and ischialgia (29.7\%), neuralgia (22.0\%) and osteoporosis $(18.7 \%)$. Cancer $(2.8 \%)$, diabetes $(13.6 \%)$ stroke $(7.5 \%)$, and cataracts $(17.8 \%)$ also occurred at a significant frequency. The most frequently registered complaint of those who were suffering from chronic 
Table 3. Types of chronic diseases that the elderly have

\begin{tabular}{|c|c|c|}
\hline Categories & $\begin{array}{c}\text { Fre- } \\
\text { quency }\end{array}$ & $\%$ \\
\hline Cancer & 93 & 2.8 \\
\hline Arthritis & 1400 & 42.7 \\
\hline Backache and ischial ache & 974 & 29.7 \\
\hline Disc & 394 & 12.0 \\
\hline Neuralgia & 721 & 22.0 \\
\hline Osteoporosis & 612 & 18.7 \\
\hline Peptic ulcer & 526 & 16.0 \\
\hline Chronic hepatitis & 58 & 1.8 \\
\hline Diabetic mellitus & 447 & 13.6 \\
\hline Thyroid disease & 53 & 1.6 \\
\hline Hypertension & 1316 & 40.1 \\
\hline Hypotension & 139 & 4.2 \\
\hline Stroke & 244 & 7.5 \\
\hline Angina pectoris & 225 & 6.9 \\
\hline Pulmonary tuberculosis & 31 & 0.9 \\
\hline Chronic bronchitis & 247 & 7.5 \\
\hline Asthma & 202 & 6.2 \\
\hline Cataract & 584 & 17.8 \\
\hline Glaucoma & 61 & 1.9 \\
\hline Chronic otitis media & 32 & 1.0 \\
\hline Chronic kidney disease & 56 & 1.7 \\
\hline Anemia & 497 & 15.2 \\
\hline Dermatosis & 216 & 6.6 \\
\hline Fracture & 390 & 11.9 \\
\hline \multicolumn{3}{|l|}{ Types of difficulties due to chronic diseases } \\
\hline Limited capability in the activities of daily living & 606 & 43.3 \\
\hline Limited capability in personal care & 13 & 0.9 \\
\hline Financial difficulty due to medical expenses & 314 & 22.4 \\
\hline Loneliness and the loss of self-esteem & 222 & 15.8 \\
\hline Limited capability in social activities & 238 & 17.0 \\
\hline
\end{tabular}

diseases was limited capability with regard to activities of daily living $(43.3 \%)$ followed by economic difficulties $(22.4 \%)$.

\section{Determining Factors for the Life Satisfaction by the Elderly}

In order to identify the factors that determine life satisfaction in elderly individuals, we conducted hierarchical multiple regression analysis for each gender. The results of analysis from the final model after the introduction of 19 variables in 8 factors showed statistically similar explanatory power in men (adj. $\mathrm{R}^{2}=0.320$ ) and in women (adj. $\mathrm{R}^{2}=0.346$ ), although a slightly higher value was noted in women (Table 4,5). The most influential factor was the individual's economic situation, the standardized B value of which was 0.278 in men and 0.336 in women, thus indicating a greater influence of the coefficient in women, and the next greatest influence was health condition as compared with the same age group, for which the B value was 0.203 in men and 0.147 in women. Other variables with high regression coefficient values include the experience (or lack thereof) of health checkups for men, with a B value of 0.128 and efforts to maintain a nutritional diet in women with a B value of 0.145 .

All three of the variables assessed in this study-chronic diseases, age-identity, and social activities-yielded statistically significant results. Life satisfaction appeared to increase with a decreasing number of chronic diseases diagnosed by doctors. It is worthy of note that the coefficient values in women were twice as high as the values recorded in men $(B=-0.108)$. The social support factor was analyzed via the introduction of the frequency of contact with children who function as direct care providers and the involvement (or noninvolvement) in social activities to the model. The results showed that $B$ values in both men and women were within the range of $0.044-0.077$, which is reflective of significant explanatory power. When asked about the age at which one enters the elderly stage, as a part of the question on the age-identity of the elderly, no significant results were observed in men, but women tended to perceive a higher contentment with life as they perceived the beginning of the elderly stage as occurring at a younger age. These results can be interpreted in that, although physical age has a greater effect on men in terms of their life satisfaction, emotional age is more critical to women in terms of their life satisfaction.

The differences in the results observed in men and women can be summarized as follows: First, life satisfaction was better in men as they grew older ( $B=0.008$ ), but this effect was not statistically significant in women. Second, unlike men, women evidenced significant family structure effects $(B=0.079)$, reporting higher life satisfaction when residing with their children. Third, unlike women, men experienced a higher degree of life satisfaction when they were smokers $(B=0.073)$. However, this may be more rightfully interpreted as a characteristic of the health behavior of men, rather than as an objective factor determining life satisfaction. Fourth, the introduction of CF and ADL yielded no significant effects on life satisfaction in men, but, in women, higher ADL points, which are reflective of easier daily living, resulted in a statistically significantly higher level of life satisfaction.

Finally, an investigation into the changing trends of the explanatory power of the $\mathrm{R}^{2}$ value using hierarchical models demonstrated that the most influential factor in life satisfaction was observed in model II in both men and women. In this model, in which economic situation and education level were introduced, the increase in the explanatory power of $R^{2}$ power was measured at 0.216 
Table 4. The multiple linear regression model: effect analysis of chronic disease, socioeconomic status, and social support on the life satisfaction among the elderly (male)

\begin{tabular}{|c|c|c|c|c|c|c|c|}
\hline Variables & Model I & Model II & Model III & Model IV & Model V & Model VI & Model VII \\
\hline Age & 0.016 & $0.060^{*}$ & $0.067^{\star}$ & $0.065^{*}$ & $0.065^{*}$ & $0.069^{*}$ & $0.080^{+}$ \\
\hline Marital status" & $0.177^{+}$ & $0.150^{+}$ & $0.152^{+}$ & $0.154^{+}$ & $0.144^{+}$ & $0.143^{+}$ & $0.120^{+}$ \\
\hline Education level" & & $0.147^{+}$ & $0.145^{\ddagger}$ & $0.133^{+}$ & $0.081^{+}$ & $0.077^{+}$ & $0.068^{*}$ \\
\hline Employment status" & & 0.038 & 0.031 & 0.043 & 0.005 & 0.006 & 0.007 \\
\hline Economic situation" & & $0.412^{+}$ & $0.397^{+}$ & $0.394^{+}$ & $0.303^{+}$ & $0.302^{\ddagger}$ & $0.278^{+}$ \\
\hline Type of household" & & & 0.048 & 0.049 & 0.032 & 0.029 & 0.026 \\
\hline Existence or not of persons needing care & & & $0.067^{\star}$ & $0.067^{*}$ & 0.039 & 0.036 & 0.041 \\
\hline Smoking" & & & & 0.012 & -0.010 & -0.007 & -0.007 \\
\hline Drinking" & & & & 0.031 & $0.062^{*}$ & $0.062^{*}$ & $0.073^{+}$ \\
\hline Exercise ${ }^{\pi}$ & & & & 0.043 & -0.011 & -0.008 & -0.030 \\
\hline Degree of nutritional diet" & & & & & $0.120^{+}$ & $0.118^{+}$ & $0.107^{+}$ \\
\hline Reception or not of health checkup & & & & & $0.126^{+}$ & $0.129^{+}$ & $0.128^{\ddagger}$ \\
\hline $\begin{array}{l}\text { Health condition compared with the same } \\
\text { age group" }\end{array}$ & & & & & $0.225^{+}$ & $0.205^{+}$ & $0.203^{+}$ \\
\hline Number of chronic diseases & & & & & & $-0.053^{*}$ & $-0.058^{\star}$ \\
\hline ADL & & & & & & -0.011 & -0.019 \\
\hline Cognitive function & & & & & & -0.006 & 0.003 \\
\hline Perception on the age of the elderly & & & & & & & 0.038 \\
\hline Frequency of contact with children & & & & & & & $0.061^{*}$ \\
\hline Performance or not of social activities & & & & & & & $0.077^{+}$ \\
\hline Adj. $R^{2}$ & 0.029 & 0.245 & 0.249 & 0.250 & 0.321 & 0.322 & 0.320 \\
\hline Change in Adj. $\mathrm{R}^{2}$ & & +0.216 & +0.004 & +0.001 & +0.071 & +0.001 & -0.002 \\
\hline
\end{tabular}

ADL: activities of daily living, Adj: adjusted.

${ }^{*} \mathrm{p}<0.05,{ }^{+} \mathrm{p}<0.01,{ }^{*} \mathrm{p}<0.001$.

Dependent variable: Likert scale (1 being the lowest life satisfaction; 5 being the highest).

"Binary variables: reference groups are those who have lower life satisfaction or lower conditions.

'Continuous variables: 3-point or 5-point Likert's scale (The higher the Likert's scale, the better life satisfaction).

The suggested figures in all cells are standardized $B$.

Table 5. The multiple linear regression model: effect analysis of chronic disease, socioeconomic status, and social support on the life satisfaction among the elderly (female)

\begin{tabular}{|c|c|c|c|c|c|c|c|}
\hline Variables & Model I & Model II & Model III & Model IV & Model V & Model VI & Model VII \\
\hline Age & -0.012 & 0.031 & 0.027 & 0.038 & 0.025 & 0.025 & 0.018 \\
\hline Marital status" & $0.110^{+}$ & $0.059^{+}$ & $0.066^{+}$ & $0.071^{\neq}$ & $0.071^{\neq}$ & $0.070^{\neq}$ & $0.065^{+}$ \\
\hline Education level" & & $0.123^{+}$ & $0.121^{\ddagger}$ & $0.112^{+}$ & $0.075^{+}$ & $0.079^{+}$ & $0.069^{+}$ \\
\hline Employment status" & & 0.014 & 0.021 & 0.030 & -0.001 & -0.002 & -0.001 \\
\hline Economic situation" & & $0.465^{+}$ & $0.445^{+}$ & $0.441^{+}$ & $0.350^{+}$ & $0.349^{+}$ & $0.336^{+}$ \\
\hline Type of household" & & & $0.097^{+}$ & $0.099^{+}$ & $0.082^{+}$ & $0.082^{\ddagger}$ & $0.079^{+}$ \\
\hline Existence or not of persons needing care & & & 0.035 & 0.031 & 0.000 & 0.007 & 0.004 \\
\hline Smoking" & & & & 0.027 & 0.018 & 0.022 & 0.015 \\
\hline Drinking" & & & & -0.023 & 0.001 & 0.000 & -0.004 \\
\hline Exercise" & & & & $0.064^{+}$ & 0.018 & 0.018 & 0.004 \\
\hline Degree of nutritional diet" & & & & & $0.161^{+}$ & $0.155^{\ddagger}$ & $0.145^{+}$ \\
\hline Reception or not of health checkup" & & & & & $0.039^{*}$ & $0.042^{*}$ & $0.045^{*}$ \\
\hline $\begin{array}{l}\text { Health condition compared with the same } \\
\text { age group" }\end{array}$ & & & & & $0.197^{\ddagger}$ & $0.150^{\neq}$ & $0.147^{\ddagger}$ \\
\hline Number of chronic diseases & & & & & & $-0.096^{+}$ & $-0.108^{+}$ \\
\hline ADL & & & & & & $0.054^{+}$ & $0.049^{*}$ \\
\hline Cognitive function & & & & & & 0.036 & 0.038 \\
\hline Perception on the age of the elderly & & & & & & & $0.040^{*}$ \\
\hline Frequency of contact with children & & & & & & & $0.044^{*}$ \\
\hline Performance or not of social activities & & & & & & & $0.064^{+}$ \\
\hline Adj. $R^{2}$ & 0.012 & 0.262 & 0.270 & 0.274 & 0.331 & 0.341 & 0.346 \\
\hline Change in Adj. $\mathrm{R}^{2}$ & & +0.250 & +0.008 & +0.004 & +0.057 & +0.010 & +0.005 \\
\hline
\end{tabular}

ADL: Activities of Daily Living, Adj: Adjusted.

${ }^{*} p<0.05,{ }^{+} p<0.01,{ }^{+} p<0.001$.

Dependent variable: Likert scale ( 1 being the lowest life satisfaction; 5 being the highest).

"Binary variables: reference groups are those who have lower life satisfaction or lower conditions.

"Continuous variables: 3-point or 5-point Likert's scale (The higher the Likert' s scale, the better life satisfaction).

The suggested figures in all cells are standardized $\mathrm{B}$. 
in men and 0.250 in women. The explanatory power was largely maintained until the final model, in which the other factors were controlled. The next largest increase of explanatory power was observed in model $\mathrm{V}$, to which the following factors were introduced: effort to maintain a nutritional diet, adherence (or not) to a health checkup schedule, and health condition as compared with the same age group.

\section{DISCUSSION}

The principal gerontologic issue in Korea is the aging of the productive population, as opposed to the aging in general. This coincides with the argument that physical functions that allow the elderly to lead independent lives, as well as social participation, which facilitates vitality in the lives of elderly individuals, are the most crucial factors for successful aging [21]. Additionally, after expanding the previous classification of aging, and dividing it into the categories of pathologic aging and normal (non-pathological) aging, some researchers are currently proposing a further subdivision of the phenomenon of normal aging into the subconcepts of 'ordinary aging' and 'successful aging'. 'productive aging', in particular, focuses on economic availability as an aspect of successful aging [1]. Advocates of this view have argued that elderly individuals must play a specific role in society, and that the aging process must involve a process whereby the elderly can become 'the young elderly'.

Aging is, in fact, accompanied by changes in a variety of factors, including not only socio-economic status after retirement, but health, caring, sense of age, and the existence of social support groups. Although these factors have yet to be well characterized in economically active populations, they appear to induce considerable changes in the components of life as one reaches the age when aging begins to be an undeniable and relevant fact. Especially, physical health is a crucial factor in the formation of personality and the performance of social activities. Thus, more elderly adults tend to become more concerned with health, as they tend to perceive their own subjective physical age as younger than it objectively is [5].

Health and longevity are associated with the provision and reception of social supports. According to the definition established by the MeSH, social supports can be defined as "supporting systems that provide help and supplement physical or mental disabilities for individuals, helping them to lead better lives". Recent studies concerning social activities have found that social activities contribute as profoundly as physical activities to the improvement of health and physical functions and the reduction of the mortality rate $[22,23]$. In short, social participation refers to involvement in regular activities while maintaining close relationships with others. This performs a crucial function in the formation of positive 'age-identity' in the elderly, and also constitutes a significant factor in the improvement of health $[24,25]$. The principal objective of this study was to understand the age-identity in the aging society by exploring a variety of factors that constitute life satisfaction in the elderly during the aging process.

The results of our analysis demonstrated that economic position and health condition compared with the same age group were the most important factors determining levels of life satisfaction levels among elderly individuals. The effects of economic situation were observed commonly in men and women, as the degree of material affluence is the principal condition required for wellbeing in the elderly stage of life, as well as for access to medical care for the treatment of diseases. Additionally, the effects of health condition compared with the same age group were observed commonly in both men and women, as chronic diseases, $\mathrm{ADL}$, and CF exert a direct effect on the individual's sense of happiness in the elderly stage.

However, a clear difference between men and women was noted in terms of the other factors. First, men tend to consider physical requirements as being more important, whereby subjective perceptions of health and adherence (or not) to a health checkup schedule evidenced the most profound effect, whereas women consider the maintenance of a nutritional diet and activities of daily living to be the most crucial factors. Second, although social support and the number of chronic diseases were found to be significant variables in both men and women, women were found to be more sensitive to them and were also more independent in terms of recognizing their own age-identity. However, men tend to base their perceptions on the health conditions of others at similar ages, and women tend to be more sensitive about their own physical aging, performance in daily living, and experiences with chronic diseases.

The increased prevalence rate of a variety of chronic diseases involving the musculoskeletal system, cardiovascular system, digestive system, respiratory system, and endocrine system in the elderly stage of life generally precipitates a decline in physical function. This decline in physical functions, in turn, affects levels of life satisfaction in elderly individuals $[13,26,27]$. The effects 
of social supports and activities on life satisfaction are associated with a variety of health conditions, as confirmed in this study. Differences have been noted with regard to psychological diseases, blood pressure, and the use of medical services. Significant effects of the degree of social networking have also been observed, even in long-term studies in which the gender and initial health condition were controlled [28,29].

From the perspective of age-identity, people generally tend to consider themselves as old when they begin to experience chronic diseases. However, people also like to perceive themselves as being younger than they really are during the aging process, which is reflective of a protective attitude toward one's own positive self-image and attempts to part with the social stigma associated to being 'old' [30]. Additionally, elderly people must be provided with opportunities to pursue a comprehensive approach to aging with regard to the popular image of 'the young elderly', social supports, and the formation of age-identity--as successful aging is only possible when the life of the aged is clearly understood [30].

Aging can result in various forms of conflict and alienation within the aged society [1]. Korea is also suffering from social turmoil associated with an increasingly elderly population. Lack of understanding and distortions against the elderly are causing social conflict as a part of that process. In order to overcome the vague fears of old age that pervade society, it is necessary to analyze and positively identify the factors relevant to their lives. The subjective meaning of aging is determined, in this study, on the basis of the life satisfaction model. Our study of life satisfaction, which refers to a feeling of happiness, may become a basis for the formulation of policies to improve the quality of elderly individuals' lives, by better understanding the elderly.

Limitations of this study are as follows. First, some variables used for the analysis have lack of objectivity to measure or the methods of measurement due to the restriction of sources. The measure of "exercise" is much simpler than common measurement methods, and the "number of chronic disease" used self-reported response. However, the validity of degree of exercise was investigated related to feasibility of smoking and drinking, and the chronic diseases were examined as self-reported but included only the cases of being diagnosed clinically to pursuit strictness in the sources. Second, even though the research model about the satisfaction of life is based on the rationale, the previous studies are limited compared to QoL, and the various configuration factors are not comprehended enough. So, the proposed model and interesting variables in this study is needed to increase the validity of contents through the continued verification.

This study attempted to explore the aging phenomena that now characterize much of Korean society, and assessed issues associated with the life satisfaction experienced during the process of aging. The results of our analysis showed that the existence of chronic diseases, the individuals' subjective sense of ageidentity, social activities, and the degree of nutritional diet all exert statistically significant effects on life satisfaction. These factors represent crucial subjective indices with regard to our understanding and acceptance of the aging process in elderly individuals. As a rapid increase in the aging population is currently underway, the amount of study conducted thus far regarding life satisfaction in the elderly cannot be considered sufficient; therefore, sustainable studies will be necessary in the future.

\section{CONFLICT OF INTEREST}

The authors have no conflict of interest to declare on this study.

\section{REFERENCES}

1. Park KS. Aged Society: The Future Progressed Already. Seoul, Eui-Am Publications, 2003. (Korean)

2. Choe H, Kim HJ, Jin KN, Joo KS, Lee KS, Sohn MS. Health status and the quality of life of the rural elderly. Korean J Health Policy Adm 1998; 8(2): 149-165. (Korean)

3. Park KN. Gender differences in the life satisfaction of elderly. J Korea Gerontol Soc 2004; 24(3): 13-29. (Korean)

4. Lee SG, Jeon SY. The relations of socioeconomic status to health status, health behaviors in the elderly. J Prev Med Public Health 2005; 38(2): 154-162. (Korean)

5. Rowe JW, Kahn RL. Successful Aging. NY: Pantheon Books, 1998.

6. Hellström Y, Hallberg IR. Perspectives of elderly people receiving home help on health, care and quality of life. Health Soc Care Community 2001; 9(2): 61-71.

7. Kim YJ, Choi HK. Family caregiving services as social support for the elderly. J Korea Gerontol Soc 2000; 20(1): 209-223. (Korean)

8. Kim SH, Oh SS, Lee EH, Kim HJ. The chronic schizophrenic patient's quality of life: focused on stress, coping strategy, symptom, and family support. Korean $J$ Clin Psychol 2005; 24(1): 73-87. (Korean)

9. Kim YB, Park JS. A study on informal social network of 
elderly: focusing on non-kin relationship. J Korea Gerontol Soc 2006; 26(2): 261-273. (Korean)

10. Borglin G, Jakobsson U, Edberg AK, Hallberg IR. Older people in Sweden with various degrees of present quality of life: their health, social support, everyday activities and sense of coherence. Health Soc Care Community 2006; 14(2): 136-146.

11. Jang IS. The leisure type, health status, self-esteem, and social support of the elderly living alone. J Korea Acad Public Health Nurs 2006; 20(2): 130-140. (Korean)

12. Kim YJ. Body Image, Self-esteem, and Quality of Life in Grown-up Congenital Heart Patients [Thesis]. Seoul: Seoul National University, 2004. (Korean)

13. Kim TM, Lee SG, Jeon SY. The relations of social support to the health behaviors and health status in the elderly. $J$ Korean Soc Health Educ Promot 2006; 23(3): 99-119. (Korean)

14. Kim CS. Social theories and discourses on population aging. J Korea Gerontol Soc 2007; 27(3): 667-690. (Korean)

15. Coke MM, Twaite JA. The Black Elderly: Satisfaction and Quality of Later Life. NY: The Haworth Press, Inc., 1995.

16. Jung KH. Oh YH, Seok JE, Doh SR, Kim CW, Yi YK, et al. The National Survey on the State of Life and the Desire for Welfare of the Elderly. Seoul: Korea Institute for Health and Social Affairs, 2008. (Korean)

17. Neugarten BL, Havighurst RJ, Tobin SS. The measurement of life satisfaction. J Gerontol 1961; 16: 134-143.

18. Huebner ES, Dew T. Validity of the perceived life satisfaction scale. School Psycho Intl 1993; 14(4): 355360.

19. Lee JR, Park CM. Quality of life using WHOQOL-Bref in Taegu. Korean J Health Policy Adm 2000; 10(3): 129-154. (Korean)

20. Lim JY, Park J, Kang MG, Ryu SY. Quality of life and its associated factors among some elderly residents using a hall for the aged in a community. J Prev Med Public Health 2007; 40(5): 337-344.

21. Park KH, Lee YH. Association of social support and social activity with physical functioning in older persons. $J$ Prev Med Public Health 2007; 40(2): 137-144. (Korean)

22. Everard KM, Lach HW, Fisher EB, Baum MC. Relationship of activity and social support to the functional health of older adults. J Gerontol B Psychol Sci Soc Sci 2000; 55(4): S208-212.

23. Mendes de Leon CF, Glass TA, Berkman LF. Social engagement and disability in a community population of older adults. Am J Epidemiol 2003; 157(7): 633-642.

24. Westerhof GJ, Barrett AE. Age identity and subjective well-being: A comparison of the United States and Germany. J Gerontol B Psychol Sci Soc Sci 2005; 60(3): S129-136.

25. Demakakos P, Gjonca E, Nazroo J. Age identity, age perceptions, and health: Evidence from the English Longitudinal Study of Ageing. Ann N Y Acad Sci 2007; 1114: 279-287.

26. Guralnik JM, LaCroix AZ. Assessing physical function in older populations. In: Wallace RB, Woolson RF, eds. The Epidemiologic Study of the Elderly. NY: Oxford University Press, 1992, pp. 159-181.

27. Evashwick CJ. Definition of the continuum of long-term care. In: Evashwick, CJ, eds. The Continuum of Long-term Care: An Integrated Systems Approach. NY: Delmar Publishers, 1996, pp. 3-13.

28. Shye D, Mulloly JP, Freeborn DK, Pope CR. Gender differences in the relationship between social network support and mortality: A longitudinal study of an elderly cohort. Soc Sci Med 1995; 41(7): 935-947.

29. Chung SD. Residential status and depression among Korean elderly people: a comparison between residents of nursing home and those based in the community. Health Soc Care Community 2008; 16(4): 370-377.

30. Tonarelli L. Life satisfaction of older people: Fostering happiness and contentment with life in the elderly. [cited 2009 Dec 30]; Available from: URL: http://seniors-healthmedicare.suite101.com/article. cfm/life-satisfaction-ofolder-people. 